\title{
A (in)evitabilidade da espera(nça)
}

\section{Sebastiana Fadda}

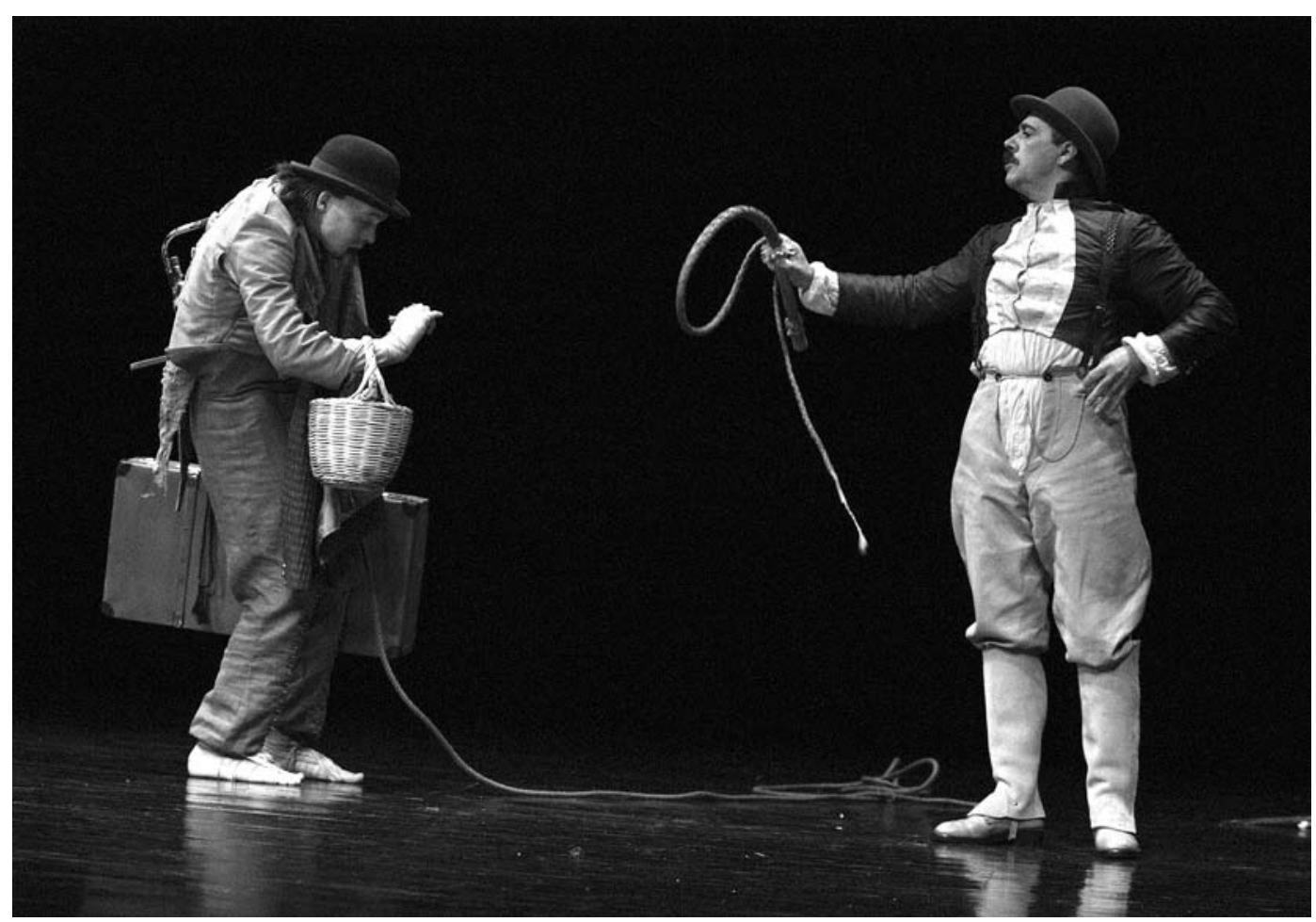

Titulo: Waiting for Godot (Ȧ espera de Godot, 1952). Autor: Samuel Beckett. Tradutor: Francisco Luis Parreira. Encenação: Miguel Seabra. Assistência artistica: Natália Luiza. Cenografia e figurinos: Ana Limpinho e Maria João Castelo. Desenho de luz: Miguel Seabra. Intérpretes: Miguel Seabra (Estragon), João Pedro Vaz (Vladimir), Pedro Gil (Lucky), António Fonseca (Pozzo) e Luis Martinho (Criança). Co-produção: Teatro Meridional - Associação Meridional de Cultura e Centro Cultural de Belém. Local e data de estreia: Lisboa, Centro Cultural de Belém, 18 de Maio de 2006.

Conforme consta na cronologia de textos de Samuel Beckett representados em Portugal que se publicou em Sinais de cena n. 5 (cronologia tão completa quanto possivel), desde a sua estreia nacional em 1959 pelo Teatro Nacional Popular dirigido por Francisco Ribeiro, são cerca de duas dúzias as diferentes produções em várias línguas e leituras de $E n$ attendant Godot a que teve acesso o público português. 0 texto, originalmente escrito em francês e publicado em 1952, estreou-se em 1953 em Paris no Théâtre Babylone, dando a seguir a volta ao mundo com um êxito que ainda perdura.

Dois anos volvidos desde a primeira aproximação ao universo beckettiano efectuada em 2004 pelo Teatro Meridional com Endgame, a experiência repetiu-se agora com Waiting for Godot (À espera de Godot). 0 subtitulo em português que se regista no programa da estreia deveuse a uma imposição unilateral da direcção do Centro Cultural de Belém, que co-produziu o espectáculo; nos restantes espaços onde este foi apresentado não ficou vestígio dessa interferência.
Se persistir na conservação dos títulos em inglês é uma opção tradutória que evidencia as ligações com o original de referência utilizado (apesar de terem sido consultadas várias fontes), voltar a Beckett por parte da companhia é um claro indício de partilha de uma visão estética que privilegia o despojamento. E neste caso tratouse de um despojamento perseguido até quase aos limites da aceitabilidade, pois da paisagem beckettiana desapareceu um elemento tão significativo como a estrada, sobrando uma árvore ressequida na direita alta da cena e um ramo torcido onde se aninha Estragon na esquerda baixa. Apesar de Miguel Seabra e Natália Luiza, no texto que escreveram para o programa, afirmarem não dar prioridade às significações extra-cénicas, o apagamento daquele elemento carrega-se de sentidos malgré soi: não há estradas, não há sentidos, não há fugas possiveis, não há caminhos, todo e qualquer caminho se equivale, toda e qualquer estrada levaria a nenhures... Mas há caminhantes, de que as botas deixadas bem visíveis no centro da ribalta são o emblema. Caminhantes que se sucedem 
Waiting for Godo de Samuel Beckett, enc. Miguel Seabra Teatro Meridional, 2006 (João Pedro Vaz e Miguel Seabra), fot. Patríia Poção / Rui Mateus.

Waiting for Godot, de Samuel Beckett, enc. Miguel Seabra, Teatro Meridional, 2006

(Miguel Seabra e João Pedro Vaz), fot. Patricia Poção / Rui Mateus. anonimamente num tempo que passa e nos consome malgré nous.

Esta omissão ${ }^{1}$ poderia assumir também outro significado, pois se o espaço de Endgame aparecia inequivocamente fechado (com longínquas hipóteses de abertura), o espaço aparentemente aberto de Waiting for Godot é assim submetido a um semelhante processo de fechamento, mantendo-se a aparente circularidade da obra ao nivel do texto e estendendo-se ao nivel do espaço cénico. Mas a geometria, como os restantes elementos que compõem o teatro beckettiano, é aleatória e variável, não oferece nenhuma garantia de estabilidade, nem de coerência. Por isso convocar a figura da espiral é mais oportuno do que apelar para o círculo: a história não se repete ciclicamente igual a si própria como pressupunha Heraclito, mas atira os homens para o vórtice de uma queda centripeta denunciada pela degradação física de Lucky e Pozzo no segundo acto da peça; o espaço, contra a lógica da dissolvência, pelo contrário, regista um movimento centrifugo, materializado nas novas folhas que despontam da árvore. Presos entre estas duas forças, os dois representantes da humanidade e da sua condição, Vladimir e Estragon, esperam. Aguardam sem desistir da espera, ou sem desesperar apesar de tudo, no meio de um caos aparentemente ordenado ou de uma ordem substancialmente caótica. Tal como afirma Gontarski,

Por certo Beckett vê a vida, quer a interior quer a exterior, como algo de caótico, absurdo, em continuo movimento, não governado por principios fundamentais. Qualquer ordem existe enquanto é criada, imposta ao homem arbitrária e artificialmente, para apaziguar a sua alma e os seus nervos. Os falaciosos e artificiais sistemas do homem - a linguagem, a matemática, a lei, a religião, a lógica naturalmente, e muitas vezes a própria arte - criam a aparência enganadora de uma ordem e a tal ponto desentendem essa realidade, que para

Beckett é simplesmente caos. (Gontarski 1992: 121; tradução minha)

Muita tinta correu sobre o teatro de Beckett, sobre os sentidos de $\dot{A}$ espera de Godot, sobre as personagens
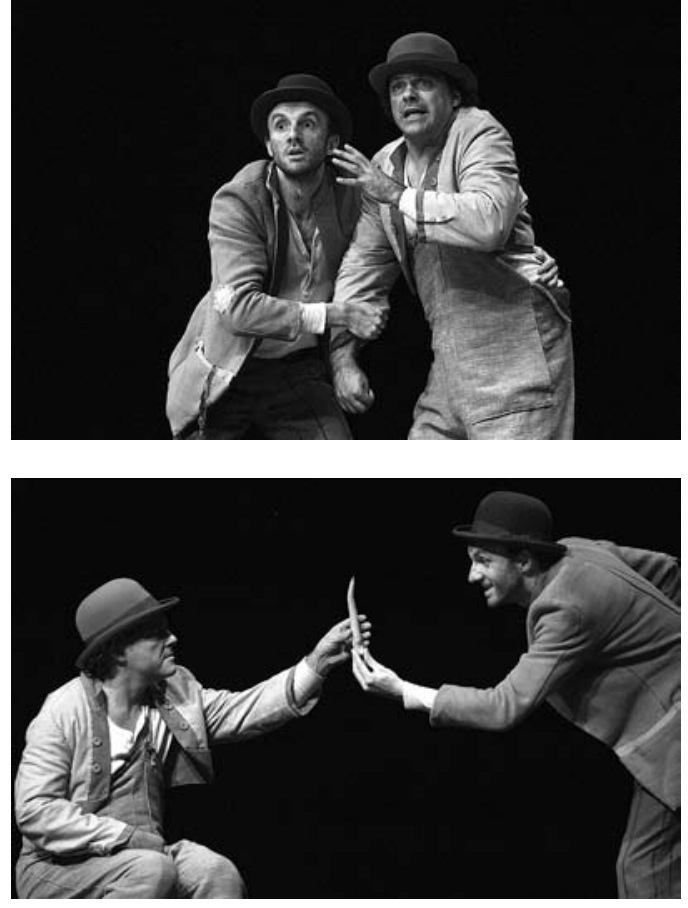

duplas e unas, complementares e antagónicas, que interagem segundo jogos de poder em que vítima e carrasco têm papéis permutáveis, precisando cada um do outro para nessa relação se validarem mutuamente. Nem é fundamental saber-se se Godot é identificável com Deus (Godo em irlandês estaria por God e teria o seu alter ego humano em Pozzo - cf. Mayoux 1997: 65), se o título corresponderia ao incipit de uma narrativa de Honoré de Balzac, se Godot é um acróstico dos nomes God e Charlot... Qualquer destas leituras parece legítima, mas talvez uma das mais contundentes, e que permite todas as restantes, é a que vê em Godot, fundamentalmente, uma "ausência" (Worton 1997: 174). Que as personagens preenchem como podem e sabem, cientes de que toda e qualquer acção ou palavra não passa de um entretenimento, um jogo tragicómico, um faz-de-conta para passar um tempo corrosivo, porque, enquanto espera, a humanidade precipita-se na espiral dantesca da degradação progressiva e inexorável. Mas há mais:

0 tempo que corre em direcção à morte representa ainda a vida, aceita-se a vida com a espera. Ȧ espera de Godot representa uma dialéctica do suicidio. (...) é evidente, como em toda a obra, que esperar significa viver. 0 suicídio aparece na obra como uma decisão racional que deveria ter sido praticada desde a primeira tomada de consciência do absurdo da vida. Se nos deixarmos arrastar pela engrenagem da"espera", nenhum momento nos parecerá decisivo. (Mayoux 1997: 73; tradução minha)

E apesar de tudo, é ainda a vida que este espectáculo celebra. Interpelado sobre o significado da peça, o autor respondeu que o que queria dizer foi exactamente o que disse. Da mesma forma, no já referido programa do espectáculo, Miguel Seabra e Natália Luiza apropriam-se das palavras beckettianas para afirmarem o direito do Teatro Meridional de não acrescentar nada ao que já foi dito ou feito. Houve, isso sim, um objecto cénico admirável, que confere uma coerente continuidade artística ao programa da companhia, privilegiando o essencial do 


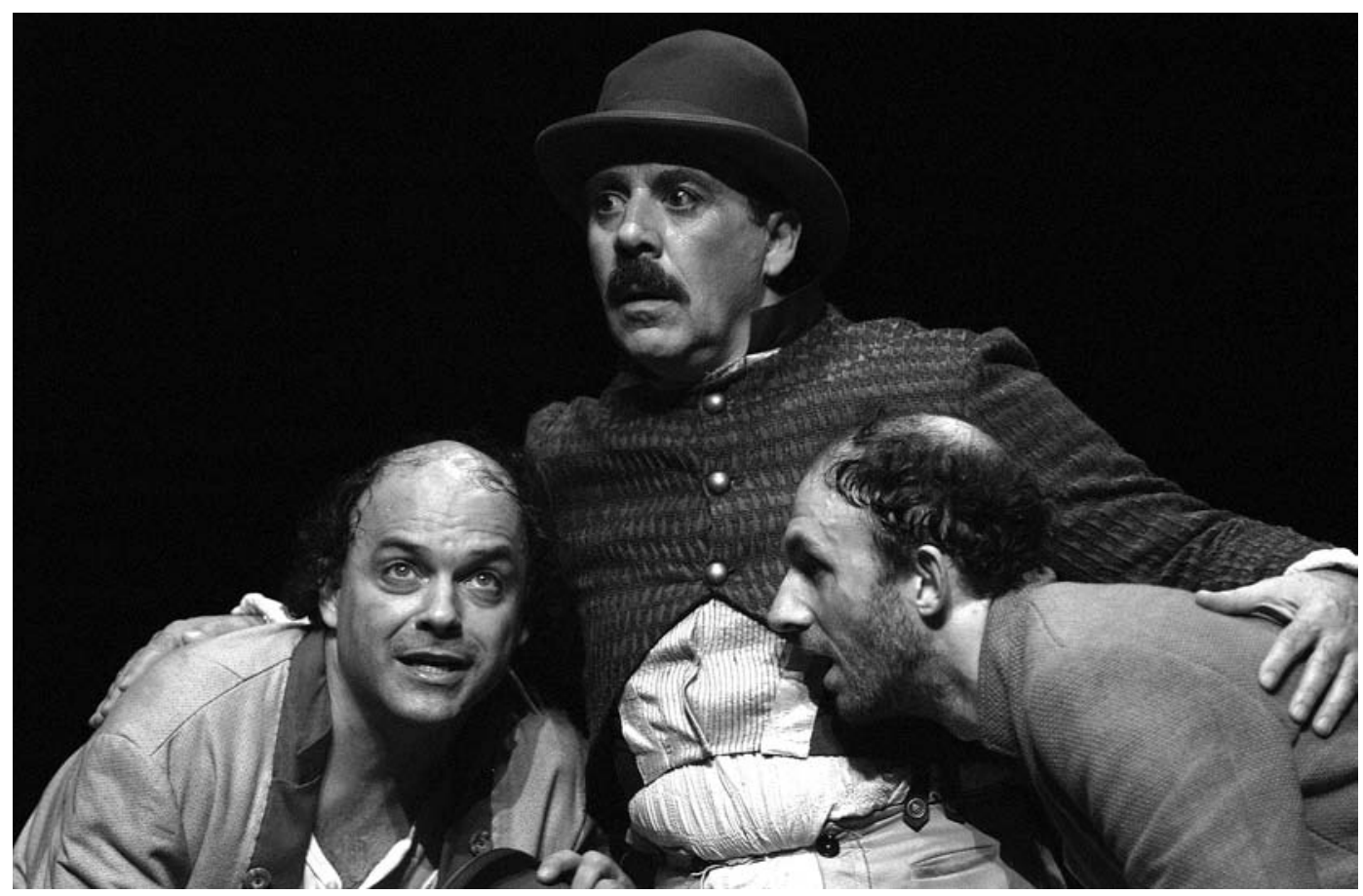

teatro tal como ela o entende: textos em que a poesia e a ternura humana são contrapontos à crueza da existência, uma entrega generosa por parte dos actores, um grande cuidado no desenho de luzes, a presença de adereços quando justificada e necessária, figurinos que reforçam a linha do espectáculo. Neste caso, é enfatizado o aspecto lúdico, quase circense, que exalta o humor negro da peça, em que os próprios conceitos de transcendência e imanência são motivo de trágica irrisão. Recuperando o percurso do Meridional, poderiamos ver em Miguel Seabra/Estragon e João Pedro Vaz/Nladimir os Clowns/Cloun Dei de Beckett/Godot.

Em relação à tradução, ainda no programa do espectáculo, Francisco Luís Parreira fornece esclarecimentos sobre as fontes utilizadas: uma edição crítica, académica, em inglês, fixada em 1994 pela Universidade de Reading; a primitiva versão francesa; uma posterior versão alemã de 1975, que contou com intervenções do autor na altura da sua encenação da peça em Berlim. 0 tradutor desmente nos factos o que afirmou numa mesa redonda sobre "Beckett Hoje", que decorreu no Fórum Municipal de Almada no dia 12 de Julho integrada no Festival Internacional de Teatro daquela cidade: "A tradução não tem mistérios. Basta traduzir o que lá está". Se fosse tão simples, pois a determinação e interpretação do "que lá está" é susceptível de ser subjectiva, tanto zelo teria sido inútil. E não o foi. Antes pelo contrário, demonstra a dignidade que merecem a tarefa, o papel e o profissionalismo dos tradutores.

A nivel de interpretação, destacou-se a profícua cumplicidade cénica estabelecida entre Miguel Seabra e João Pedro Vaz, que criaram belos diálogos sempre em aberto, bem como uma conseguida unidade de registo. Mas a tão reiterada complementaridade das duplas Vladimir/Estragon (raciocínio/emoção) e Lucky/Pozzo (servo/patrão), palpável no primeiro caso, é um pouco prejudicada no segundo. Menos feliz resultou a caracterização da outra dupla beckettiana que, apesar da surpreendente gestualidade de Pedro Gil, surge em parte comprometida pela tendência para a declamação de António Fonseca, inserindo uma nota dissonante no conjunto.

Talvez o actor beckettiano devesse transmitir cambiantes e subtilezas que passam pela interiorização não apenas da essência da personagem, mas também da palavra e do gesto enquanto matérias palpáveis e voláteis, necessárias e supérfluas ao mesmo tempo. Se a palavra é algo que dá a impressão de existir a quem a profere, 0 gesto é expressão não de um papel social ou de um estereótipo, mas de uma condição metafísica. Por isso os actores são seríssimos, sem contudo chegarem a levarse a sério, seja qual for o tom em que estejam a actuar. É neste sentido que interpreto as palavras de Jean Martin, que representou o papel de Lucky na estreia parisiense de 1953: "Beckett não quer que os seus actores recitem. Quer apenas que eles façam o que ele Ihes diz. Quando eles tentam recitar, fica furioso" (apud Worton 1997: 170; tradução minha).

Ainda uma nota: é de encorajar o trabalho do jovem Luis Martinho, cuja origem africana reitera o interesse e a vocação pela lusofonia do Teatro Meridional. Segura e rigorosa é a encenação de Miguel Seabra. Será que nos voltará a levar na direcção da humanidade beckettiana? Isto é: ao reencontro da nossa própria humanidade e à dos nossos semelhantes? Esperemos.

\section{Referências bibliográficas}

\section{GONTARSKI, Stanley E. (1997), "L'estetica del disfacimento", in Sergio}

Colomba (a cura di), Le ceneri della commedia, Roma, Bulzoni Editore, pp. 107-133.

MAYOUX, Jean-Jacques (1997), "Parodia d'azione, parodia di teatro", in Sergio Colomba, op.cit., pp. 57-81.

PROGRAMA (2006), "Waiting for Godot (À espera de Godot), de Samuel Beckett pelo Teatro Meridional", Lisboa, Centro Cultural de Belém.

WORTON, Michael (1997), "II teatro come testo", in Sergio Colomba, op.cit,, pp. 169-195. 